\title{
Assessment of Liver Fibrosis with Diffusion-Weighted Magnetic Resonance Imaging Using Different b-values in Chronic Viral Hepatitis
}

\author{
Ercan Kocakoc ${ }^{a}$ Ayse Ahsen Bakan ${ }^{a}$ Orhan Kursat Poyrazoglu ${ }^{b}$ \\ Adile Ferda Daglic Yeliz Guld Mehtap Cicekci ${ }^{d}$ Ibrahim Halil Bahcecioglue \\ ${ }^{a}$ Department of Radiology, Faculty of Medicine, Bezmialem Vakif University, Istanbul, b Department of \\ Gastroenterology, Education and Research Hospital, Kayseri, ' $D e p a r t m e n t$ of Pathology, Faculty of Medicine, Inonu \\ University, Malatya, and Departments of ${ }^{\mathrm{d}}$ Radiology and ${ }^{\mathrm{e}}$ Gastroenterology, Faculty of Medicine, Firat University, \\ Elazig, Turkey
}

\section{Key Words}

Hepatitis · Fibrosis · Liver · Diffusion-weighted imaging

\begin{abstract}
Objective: To examine the effectiveness of apparent diffusion coefficient (ADC) values and to compare the reliability of different $b$-values in detecting and identifying significant liver fibrosis. Subjects and Methods: There were 44 patients with chronic viral hepatitis $(\mathrm{CVH})$ in the study group and 30 healthy participants in the control group. Diffusion-weighted magnetic resonance imaging (DWI) was performed before the liver biopsy in patients with $\mathrm{CVH}$. The values of ADC were measured with 3 different b-values $(100,600,1,000 \mathrm{~s} /$ $\mathrm{mm}^{2}$ ). In addition, liver fibrosis was classified using the modified Ishak scoring system. Liver fibrosis stages and ADC values were compared using areas under the receiver-operating characteristic (ROC) curve. Results: The study group's mean ADC value was not statistically significantly different from the control group's mean ADC value at $b=100 \mathrm{~s} / \mathrm{mm}^{2}$ $\left(3.69 \pm 0.5 \times 10^{-3}\right.$ vs. $\left.3.7 \pm 0.3 \times 10^{-3} \mathrm{~mm}^{2} / \mathrm{s}\right)$ and $\mathrm{b}=600 \mathrm{~s} /$ $\mathrm{mm}^{2}\left(2.40 \pm 0.3 \times 10^{-3}\right.$ vs. $\left.2.5 \pm 0.5 \times 10^{-3} \mathrm{~mm}^{2} / \mathrm{s}\right)$. However, the study group's mean ADC value $\left(0.99 \pm 0.3 \times 10^{-3} \mathrm{~mm}^{2} / \mathrm{s}\right)$ was significantly lower than that of the control group (1.2 \pm $\left.0.1 \times 10^{-3} \mathrm{~mm}^{2} / \mathrm{s}\right)$ at $b=1,000 \mathrm{~s} / \mathrm{mm}^{2}$. With $\mathrm{b}=1,000 \mathrm{~s} / \mathrm{mm}^{2}$
\end{abstract}

and the cutoff ADC value of $0.0011 \mathrm{~mm}^{2} / \mathrm{s}$ for the diagnosis of liver fibrosis, the mean area under the ROC curve was $0.702 \pm 0.07(p=0.0015)$. For $b=1,000 \mathrm{~s} / \mathrm{mm}^{2}$ and the cutoff $A D C$ value of $0.0011 \mathrm{~mm}^{2} / \mathrm{s}$ to diagnose significant liver fibrosis (Ishak score $=3$ ), the mean area under the ROC curve was $0.759 \pm 0.07(p=0.0001)$. Conclusion: Measurement of $A D C$ values by DWI was effective in detecting liver fibrosis and accurately identifying significant liver fibrosis when a b-value of $1,000 \mathrm{~s} / \mathrm{mm}^{2}$ was used.

(c) 2015 S. Karger AG, Basel

\section{Introduction}

Hepatic fibrosis develops primarily as a consequence of chronic viral hepatitis (CVH). As fibrosis progresses, it can result in cirrhosis and end-stage liver diseases $[1,2]$ making it vitally important to diagnose fibrosis before patients develop early or established cirrhosis. Liver biopsy is the gold standard for staging liver fibrosis and evaluating necroinflammatory changes $[1,3]$. However, liver biopsy is an invasive method and has inherent risks exemplified by bleeding. Additionally, biopsy is limited by interobserver variability and sampling error $[4,5]$. Because of these limitations, noninvasive methods, for in-

\begin{tabular}{ll}
\hline KARGER 125\% & $\begin{array}{l}\text { (1) 2015 S. Karger AG, Basel } \\
\text { 1011-7571/15/0246-0522\$39.50/0 Openger }\end{array}$ \\
$\begin{array}{l}\text { E-Mail karger@karger.com } \\
\text { www.karger.com/mpp }\end{array}$ & $\begin{array}{l}\text { This is an Open Access article licensed under the terms of the } \\
\text { Creative Commons Attribution-NonCommercial 3.0 Un- } \\
\text { ported license (CC BY-NC) (www.karger.com/OA-license), } \\
\text { applicable to the online version of the article only. Distribu- } \\
\text { tion permitted for non-commercial purposes only. }\end{array}$
\end{tabular}

Ayse Ahsen Bakan

Department of Radiology

Faculty of Medicine, Bezmialem Vakif University

TR-34093 Fatih, Istanbul (Turkey)

E-Mail ahsen80@hotmail.com 
stance current imaging modalities, e.g. transient elastography (fibroscan) and magnetic resonance (MR) elastography, and a fibrotest are being investigated for identifying and staging fibrosis [6-10]. More recently, the utility of diffusion-weighted MR imaging (MRI; DWI), an advanced MRI technique, in the detection and staging of liver fibrosis has also been evaluated.

The DWI is a specific MRI technique that evaluates the motion of, mainly, water protons in the tissue. The apparent diffusion coefficient (ADC) is the most frequently used DWI measure and provides useful information about inflammation, perfusion and local cell breakdown. The ADC map is calculated based on exponential fitting of DWI over multiple b-values and is used to measure diffusion quantitatively. Prior studies have shown that in liver fibrosis water diffusion may be diminished by extracellular collagen fibers and proteoglycans, thus, reduced ADC values have been reported for liver fibrosis $[1,10$ 18]. These findings suggest DWI could be a useful imaging technique to evaluate fibrosis. In more recent studies, researchers examined the relationship between the stages of hepatic fibrosis and ADC values $[1,14-16,19]$.

The goal of this study was to examine the efficacy of $A D C$ values and to compare the reliability of different $b$ values (i.e. $100,600,1,000 \mathrm{~s} / \mathrm{mm}^{2}$ ) in detecting and identifying significant liver fibrosis.

\section{Materials and Methods}

\section{Patients}

This prospective study was carried out between March 2007 and April 2009 with a study population of 44 patients (males: 28 and females: 16, age: $31-60$ years) and a control group of 30 healthy participants (male: 21 and female: 9, age: $37-67$ years). In the study population 30 patients had chronic hepatitis B, and 14 had chronic hepatitis $C$. The patient exclusion criterion was presence of steatosis or malignant liver lesions because both conditions can influence ADC values and could be confounding factors [20]. In patients with $\mathrm{CVH}$, DWI was performed followed by a liver biopsy 3-24 h later. Written informed consent was obtained from each participant, and the Institutional Research Ethics committee approved the study.

\section{Magnetic Resonance Imaging}

MRI was done using a 1.5-tesla MR system (General Electric Healthcare, Milwaukee, Wis., USA). Before the DWI examinations, fat-saturated T1-weighted axial, T1 in- and out-of-phase, fat-saturated T2-weighted axial, and single-shot fast spin echo T2weighted coronal images were performed. The DWI images were obtained at: b-values of 100,600 and $1,000 \mathrm{~s} / \mathrm{mm}^{2}$; TR/TE, 8,000/67-91; matrix, $128 \times 128$; NEX, 1.0; FOV, $24 \mathrm{~cm}$; slice thickness, $5 \mathrm{~mm}$; interslice gap, none; diffusion direction, all; acquisition time, $32 \mathrm{~s}$; coil, torso.

Assessment of Liver Fibrosis with DWI

\section{Image Analysis}

Automatic voxel-by-voxel analysis on a workstation (Software version 2.0, General Electric Medical Systems, Milwaukee, Wis., USA) was used to obtain gray-scale and color-coded ADC maps for the b-values of 100, 600 and 1,000 s/ $\mathrm{mm}^{2}$. Maps of the liver parenchyma were evaluated by an experienced abdominal radiologist (E.K.). The ADC values were measured by locating 3 round regions of interest (ROIs) approximately $1 \mathrm{~cm}$ in diameter in the right lobe of the liver, excluding large vessels and motion artifacts (fig. 1-3). For each liver lobe, the final ADC value was calculated as the average of the $\mathrm{ADC}$ values obtained from the 3 ROIs.

\section{Histopathology}

Eighteen-gauge ultrasound-guided core biopsy was carried out on the right liver lobe. An experienced histopathologist (A.F.D) evaluated the specimens in accordance with the modified Ishak scoring system. The staging system scored fibrosis levels continuously from stage 0 to stage 6 . The scores were identified as follows: F0 = no fibrosis; F1 = fibrous expansion of some portal areas with or without short fibrous septa; F2 = fibrous expansion of most portal areas with or without short fibrous septa; F3 = fibrous expansion of most portal areas with occasional portal-to-portal bridging; F4 = fibrous expansion of most portal areas with marked bridging (portal-to-portal as well as portal-central); F5 = marked bridging (portal-to-portal and/or portal-central) with occasional nodules (incomplete cirrhosis); F6 = cirrhosis (probable or definite) [21].

\section{Statistical Analysis}

A receiver-operating characteristic (ROC) curve was used to evaluate ADC values and the stage of liver fibrosis. The ROC analysis was also performed to decide ADC cutoff values to differentiate liver fibrosis at 100, 600 and $1,000 \mathrm{~s} / \mathrm{mm}^{2}$ gradients. The optimal cutoff values that represented maximized test sensitivity and specificity using the Youden index were used. Sensitivity, specificity, positive and negative predictive values (PPV, NPV), and p values were determined using ROC analysis.

\section{Results}

Of the 44 biopsies, 23 (52.2\%) had Ishak scores of $\geq 3$ while $21(47.8 \%)$ had a score of $\leq 2$. The mean ADC values of the study and the control groups did not differ significantly from each other at b-values of $100 \mathrm{~s} / \mathrm{mm}^{2}(3.69 \pm$ $0.5 \times 10^{-3}$ vs. $\left.3.7 \pm 0.3 \times 10^{-3} \mathrm{~mm}^{2} / \mathrm{s} ; \mathrm{p}=0.257\right)$ and 600 $\mathrm{s} / \mathrm{mm}^{2}\left(2.40 \pm 0.3 \times 10^{-3}\right.$ vs. $2.5 \pm 0.5 \times 10^{-3} \mathrm{~mm}^{2} / \mathrm{s} ; \mathrm{p}=$ $0.345)$. However, at the $b$-value of $1,000 \mathrm{~s} / \mathrm{mm}^{2}$, the mean ADC value of the study group $\left(0.99 \pm 0.3 \times 10^{-3} \mathrm{~mm}^{2} / \mathrm{s}\right)$ was lower than that of the control group $\left(1.2 \pm 0.1 \times 10^{-3}\right.$ $\mathrm{mm}^{2} / \mathrm{s}$; table 1 ), and the difference was statistically significant $(\mathrm{p}=0.001)$.

For the b-value of $1,000 \mathrm{~s} / \mathrm{mm}^{2}$, when the ADC value for the detection of liver fibrosis was accepted as $\leq 0.0011$ $\mathrm{mm}^{2} / \mathrm{s}$, the mean area under the ROC curve was $0.702 \pm$ $0.07(\mathrm{p}=0.0015)$. The sensitivity, specificity, PPV and NPV were $61.3,80,81.8$ and 58.5\%, respectively (table 2; fig. 4). 


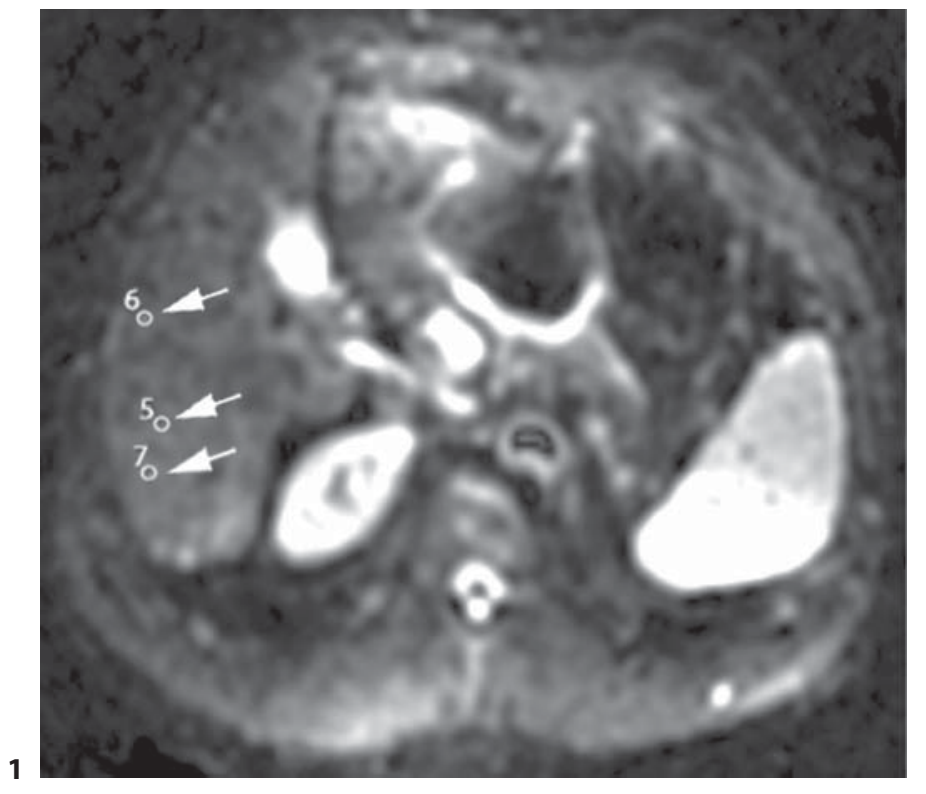

Fig. 1. Gray-scale ADC map for patient A from the study group. ADC values for the 3 ROIs at a b-value of $100 \mathrm{~s} / \mathrm{mm}^{2}$ were as follows: $3.26 \times 10^{-3}, 3.61 \times 10^{-3}$ and $3.83 \times 10^{-3} \mathrm{~mm}^{2} / \mathrm{s}$.

Fig. 2. Gray-scale ADC map for patient A from the study group. ADC values for the 3 ROIs at a b-value of $600 \mathrm{~s} / \mathrm{mm}^{2}$ were as follows: $2.60 \times 10^{-3}, 2.34 \times 10^{-3}$ and $2.05 \times 10^{-3} \mathrm{~mm}^{2} / \mathrm{s}$.

Fig. 3. Gray-scale ADC map for patient A from the study group. ADC values for the 3 ROIs at a b-value of $1,000 \mathrm{~s} / \mathrm{mm}^{2}$ were as follows: $1.48 \times 10^{-3}, 1.38 \times 10^{-3}$ and $1.36 \times 10^{-3} \mathrm{~mm}^{2} / \mathrm{s}$.

Table 1. Control and study groups' mean ADC values at b-values of 100,600 and $1,000 \mathrm{~s} / \mathrm{mm}^{2}$

\begin{tabular}{llll}
\hline & \multicolumn{2}{c}{$\mathrm{ADC}, \mathrm{n} \times 10^{-3} \mathrm{~mm}^{2} / \mathrm{s}$} & $\mathrm{p}$ \\
\cline { 2 - 3 } & $\operatorname{control}(\mathrm{n}=30)$ & $\mathrm{CVH}(\mathrm{n}=44)$ & \\
\hline $\begin{array}{llll}\mathrm{b} \text {-values, s/mm } \\
100\end{array}$ & $3.7 \pm 0.3$ & $3.69 \pm 0.5$ & 0.2571 \\
600 & $2.5 \pm 0.5$ & $2.40 \pm 0.3$ & 0.3450 \\
1,000 & $1.2 \pm 0.1$ & $0.99 \pm 0.3$ & 0.0015 \\
\hline
\end{tabular}
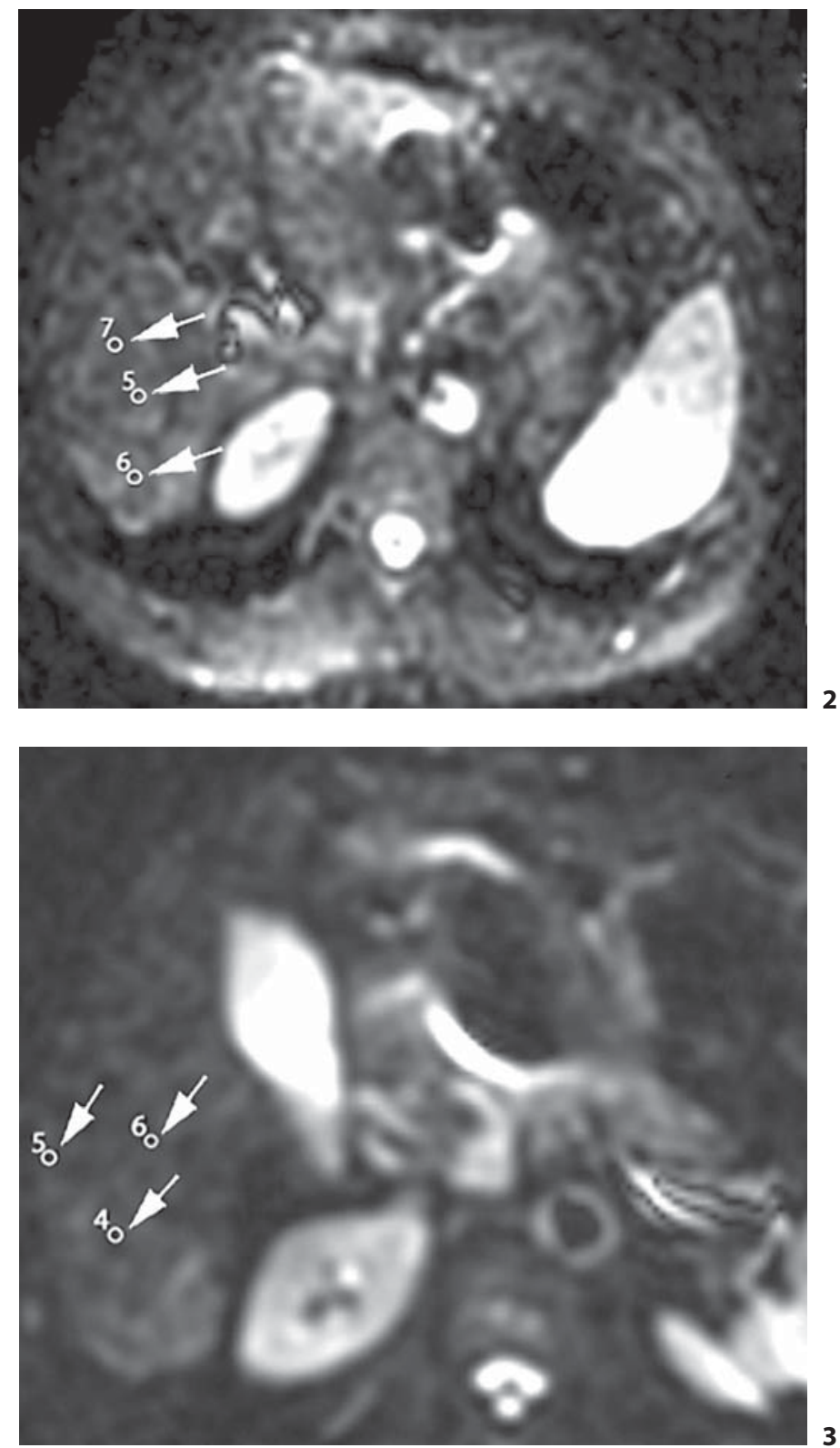

At the b-value of $1,000 \mathrm{~s} / \mathrm{mm}^{2}$, when $\leq 0.0011 \mathrm{~mm}^{2} / \mathrm{s}$ was accepted as the cutoff ADC value for the detection of significant liver fibrosis (Ishak score $\geq 3$ ), the mean area under the ROC curve was $0.759 \pm 0.07(\mathrm{p}=0.0001)$. The sensitivity, specificity, PPV and NPV were 56.5, 93.3, 86.7 and $73.7 \%$, respectively (table 2 ; fig. 5 ).

For the b-value of $1,000 \mathrm{~s} / \mathrm{mm}^{2}$, when the ADC cutoff value for the detection of fibrosis and significant liver fibrosis (Ishak score $\geq 3$ ) was accepted as $\leq 0.0009 \mathrm{~mm}^{2} / \mathrm{s}$, PPV values increased up to $100 \%$ but sensitivity and NPV values decreased (table 3 ). 


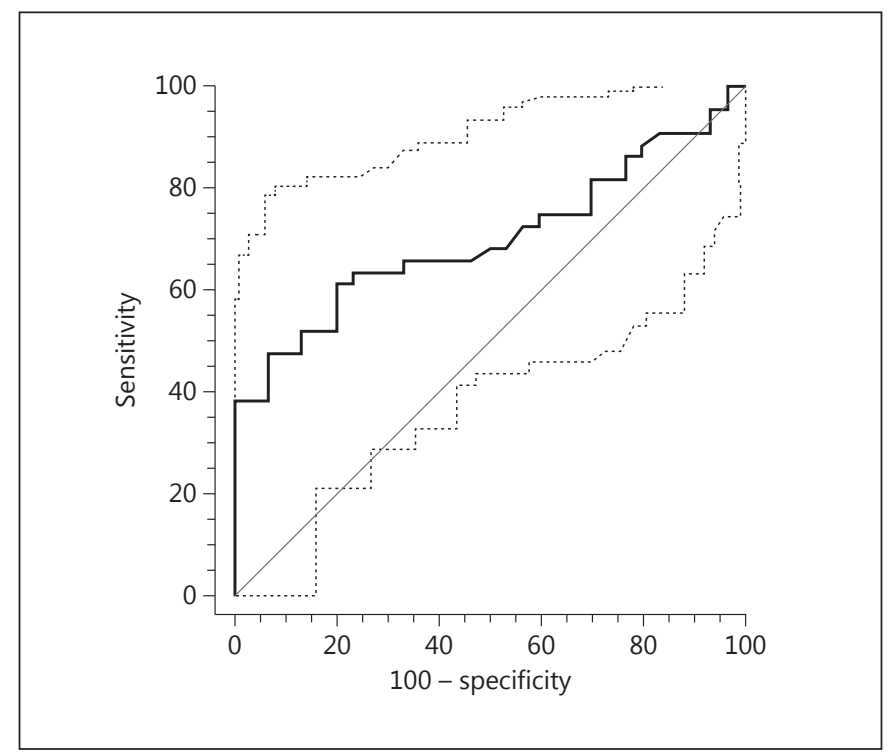

Fig. 4. ROC curve analysis of ADC values for detecting liver fibrosis at a b-value of $1,000 \mathrm{~s} / \mathrm{mm}^{2}$ and for $\mathrm{ADC} \leq 1.1 \times 10^{-3} \mathrm{~mm}^{2} / \mathrm{s}$.

Table 2. Sensitivity (Se), specificity (Sp), PPV and NPV for the detection of liver fibrosis and significant liver fibrosis (Ishak score $\geq 3$ ) at a b-value of $1,000 \mathrm{~s} / \mathrm{mm}^{2}$ and for ADC $\leq 1.1 \times 10^{-3} \mathrm{~mm}^{2} / \mathrm{s}$

\begin{tabular}{lllll}
\hline Stages & Se & Sp & PPV & NPV \\
\hline $\begin{array}{l}\text { Liver fibrosis } \\
\begin{array}{l}\text { Significant fibrosis } \\
\text { Ishak score } \geq 3\end{array}\end{array}$ & $61.3 \%$ & $80.0 \%$ & $81.8 \%$ & $58.5 \%$ \\
\hline
\end{tabular}

\section{Discussion}

In the current study the ADC values were effectively used to detect and identify significant liver fibrosis. Further, the b-value of $1,000 \mathrm{~s} / \mathrm{mm}^{2}$ was more reliable than b-values of 100 and $600 \mathrm{~s} / \mathrm{mm}^{2}$ for detecting fibrosis and significant fibrosis. The detection of significant fibrosis (Ishak score $\geq 3$ ) is clinically essential because only patients with significant liver fibrosis are considered as suitable for antiviral treatment $[22,23]$. Patients with milder fibrosis, on the other hand, are often not given an aggressive treatment due to the cost and toxicification associated with antiviral treatment [22].

Our findings are in accordance with the study of Taouli et al. [1], which showed that ADC values drawn from DWI were useful for the evaluation of liver fibrosis at b-

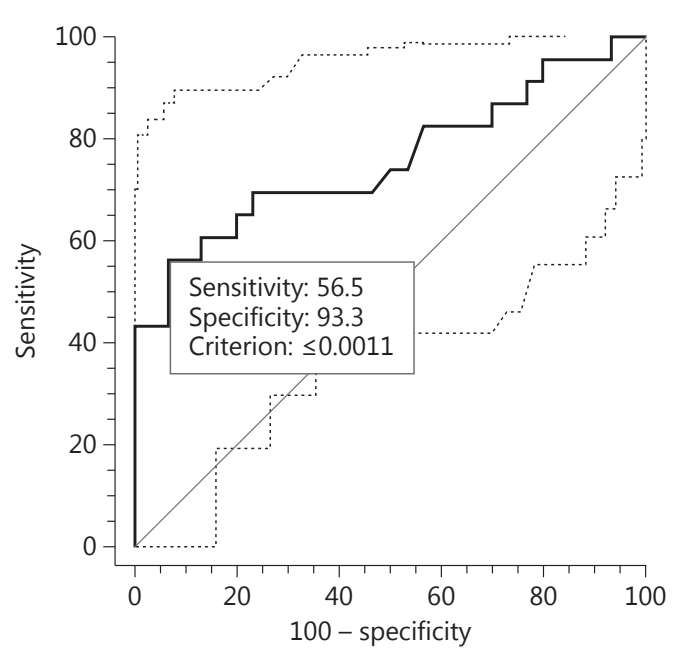

Fig. 5. ROC curve analysis of ADC values for detecting Ishak score $\geq 3$ liver fibrosis at a b-value of $1,000 \mathrm{~s} / \mathrm{mm}^{2}$ and for ADC $\leq 1.1 \times$ $10^{-3} \mathrm{~mm}^{2} / \mathrm{s}$.

Table 3. Sensitivity (Se), specificity (Sp), PPV and NPV for the detection of liver fibrosis and significant liver fibrosis (Ishak score z3) at a b-value of $1,000 \mathrm{~s} / \mathrm{mm}^{2}$ and for ADC $\leq 0.9 \times 10^{-3} \mathrm{~mm}^{2} / \mathrm{s}$

\begin{tabular}{lllll}
\hline Stages & Se & Sp & PPV & NPV \\
\hline $\begin{array}{l}\text { Liver fibrosis } \\
\text { Significant fibrosis }\end{array}$ & $31.8 \%$ & $100 \%$ & $100 \%$ & $50 \%$ \\
$\quad$ Ishak score $\geq 3$ & $43.4 \%$ & $100 \%$ & $100 \%$ & $69 \%$ \\
\hline
\end{tabular}

values of $500 \mathrm{~s} / \mathrm{mm}^{2}$ or larger. Using a sample larger than that of Taouli et al., we found that $1,000 \mathrm{~s} / \mathrm{mm}^{2}$ was more effective than the $b$-value of $600 \mathrm{~s} / \mathrm{mm}^{2}$ in detecting liver fibrosis. Our results are also in line with the study of Bakan et al. [16], in which ADC values obtained at the bvalue of $1,000 \mathrm{~s} / \mathrm{mm}^{2}$ were found to be effective in identifying significant fibrosis. Bakan et al. further concluded that at a b-value of $1,000 \mathrm{~s} / \mathrm{mm}^{2} \mathrm{ADC}$ values were helpful in differentiating between every combination of fibrosis stages except for F0 versus F1 and F1 versus F2.

Most studies that compared ADC values of fibrotic and normal livers found that patients with cirrhosis had lower ADC values than healthy participants [1, 10-18]. Sandrasegaran et al. [15], using b-values of 50 and $400 \mathrm{~s} /$ $\mathrm{mm}^{2}$, concluded that although there was a statistically significant difference between ADC values of cirrhotic 
and nonfibrotic liver, ADC values were not helpful in differentiating F2 fibrosis from lower or upper stages of fibrosis. On the other hand, Koinuma et al. [18] found a relationship between fibrosis scores and ADC values at b-values of 0 and $128 \mathrm{~s} / \mathrm{mm}^{2}$. In the study of Boulanger et al. [19] there was no statistically significant difference between ADC values of patients with hepatitis $C$ and ADC values of the control group at 5 different $b$-values changing from 50 to $250 \mathrm{~s} / \mathrm{mm}^{2}$. When interpreting the results of these 3 studies, it is important to keep in mind other findings (e.g. Le Bihan et al. $[24,25]$ and Yamada et al. [26]) that overestimated ADC values at lower b-values due to the perfusion effect. In the current study, to prevent such an overestimation larger b-values were used. Our findings suggest that ADC values at $1,000 \mathrm{~s} / \mathrm{mm}^{2}$ were more effective than $\mathrm{ADC}$ values at $b$-values of 100 and $600 \mathrm{~s} / \mathrm{mm}^{2}$ in detecting liver fibrosis.
Potential limitations of our study were that similar numbers of patients were not used at each stage of fibrosis and the activity score of hepatitis was not evaluated. Future studies with a larger sample that is distributed evenly among different stages of fibrosis are recommended although such studies could inevitably take a longer period of time than the current study.

\section{Conclusion}

Our findings showed that ADC values at $1,000 \mathrm{~s} / \mathrm{mm}^{2}$ were helpful in detecting liver fibrosis. However, b-values $<600 \mathrm{~s} / \mathrm{mm}^{2}$ could not accurately quantify liver fibrosis. Based on the accurate detection of significant fibrosis, the use of ADC values at $1,000 \mathrm{~s} / \mathrm{mm}^{2}$ could potentially be useful in making a decision about antiviral treatment.

\section{References}

1 Taouli B, Tolia AJ, Losada M, et al: Diffusionweighted MRI for quantification of liver fibrosis: preliminary experience. AJR Am J Roentgenol 2007;189:799-806.

$\checkmark 2$ Vere CC, Streba CT, Streba L, et al: Lipid serum profile in patients with viral liver cirrhosis. Med Princ Pract 2012;21:566-568.

$>3$ Berg T, Sarrazin C, Hinrichsen H, et al: Does non-invasive staging of fibrosis challenge liver biopsy as a gold standard in chronic hepatitis C? Hepatology 2004;39:1456-1457.

4 Afdhal NH, Nunes D: Evaluation of liver fibrosis: a concise review. Am J Gastroenterol 2004;99:1160-1174.

5 Kugelmas M: Liver biopsy. Am J Gastroenterol 2004;99:1416-1417.

$\checkmark 6$ Vallet-Pichard A, Mallet V, Nalpas B, et al: FIB-4: an inexpensive and accurate marker of fibrosis in HCV infection - comparison with liver biopsy and FibroTest. Hepatology 2007; 46:32-36.

7 Godfrey EM, Mannelli L, Griffin N, et al: Magnetic resonance elastography in the diagnosis of hepatic fibrosis. Semin Ultrasound CT MR 2013;34:81-88.

-8 Mannelli L, Wilson GJ, Dubinsky TJ, et al: Assessment of the liver strain among cirrhotic and normal livers using tagged MRI. J Magn Reson Imaging 2012;36:1490-1495.

10 Girometti R, Furlan A, Bazzocchi M, et al: Diffusion-weighted MRI in evaluating liver fibrosis: a feasibility study in cirrhotic patients. Radiol Med 2007;112:394-408.

11 Moteki T, Horikoshi H: Evaluation of hepatic lesions and hepatic parenchyma using diffusion-weighted echo-planar MR with three values of gradient b-factor. J Magn Reson Imaging 2006;24:637-645.

-12 Namimoto T, Yamashita Y, Sumi S, et al: Focal liver masses: characterisation with diffusion-weighted echoplanar MR imaging. Radiology 1997;204:739-744.

-13 Ichikawa T, Haradome H, Hachiya J, et al: Diffusion-weighted MR imaging with a single-shot echoplanar sequence: detection and characterization of focal hepatic lesions. AJR Am J Roentgenol 1998;170:397-402.

14 Lewin M, Poujol-Robert A, Boelle PY, et al: Diffusion-weighted magnetic resonance imaging for the assessment of fibrosis in chronic hepatitis C. Hepatology 2007;46:658-665.

15 Sandrasegaran K, Akışık FM, Lin C, et al: Value of diffusion-weighted MRI for assessing liver fibrosis and cirrhosis. AJR Am J Roentgenol 2009;193:1556-1560.

16 Bakan AA, Inci E, Bakan S, et al: Utility of diffusion-weighted imaging in the evaluation of liver fibrosis. Eur Radiol 2012;22:682-687.

9 Foucher J, Chanteloup E, Vergniol J, et al: Di- 17 Soylu A, Kılıçkesmez Ö, Poturoğlu Ş, et al: agnosis of cirrhosis by transient elastography (FibroScan): a prospective study. Gut 2006; 55:403-408.
Utility of diffusion-weighted MRI for assessing liver fibrosis in patients with chronic active hepatitis. Diagn Interv Radiol 2010;16: 204-208.
18 Koinuma M, Ohashi I, Hanafusa K, et al: Apparent diffusion coefficient measurements with diffusion-weighted magnetic resonance imaging for evaluation of hepatic fibrosis. J Magn Reson Imaging 2005;22:80-85.

19 Boulanger Y, Amara M, Lepanto L, et al: Diffusion-weighted MR imaging of the liver of hepatitis C patients. NMR Biomed 2003;16: 132-136.

20 Poyraz AK, Onur MR, Kocakoç E, Oğur E. Diffusion-weighted MRI of fatty liver. J Magn Reson Imaging 2012;35:1108-1111.

21 Ishak K, Baptista A, Bianchi L, et al: Histologic grading and staging of chronic hepatitis. J Hepatol 1995;22:696-699.

22 Kim AI, Saab S: Treatment of hepatitis C. Am J Med 2005;118:808-815.

-23 Afdhal NH: Diagnosing fibrosis in hepatitis $\mathrm{C}$ : is the pendulum swinging from biopsy to blood tests? Hepatology 2003;37:972-974.

24 Le Bihan D, Breton E, Lallemand D, et al: Separation of diffusion and perfusion in intravoxel incoherent motion MR imaging. Radiology 1988;168:497-505.

25 Le Bihan D, Johansen-Berg H: Diffusion MRI at 25: exploring brain tissue structure and function. Neuroimage 2012;61:324-341.

26 Yamada I, Aung W, Himento Y, et al: Diffusion coefficients in abdominal organs and hepatic lesions: evaluation with intravoxel incoherent motion echo-planar MR imaging. Radiology 1999;210:617-623. 